\title{
NEW DOUBLE CURRENT CONTROLLED CFA (DCC-CFA) BASED VOLTAGE-MODE OSCILLATOR WITH INDEPENDENT ELECTRONIC CONTROL OF OSCILLATION CONDITION AND FREQUENCY
}

\author{
Roman Šotner ${ }^{*}$ - Norbert Herencsár ${ }^{* *}$ \\ Jan Jeřábek ${ }^{* *}$ — Radek Dvořák ${ }^{*}$ - Aslihan Kartci ${ }^{* * *}$ \\ — Tomáš Dostál * Kamil Vrba ${ }^{* *}$
}

\begin{abstract}
In this paper, a new electronically tunable quadrature oscillator (ETQO) based on two modified versions of current feedback amplifiers (CFAs), the so called double current controlled CFA (DCC-CFAs) is presented. The frequency of oscillation (FO) of the proposed voltage-mode (VM) ETQO is electronically adjustable by current gain or by varying the intrinsic resistance of the $\mathrm{X}$ terminal of the active element used. The condition of oscillation (CO) is adjustable by current gain independently with respect to frequency of oscillation. Simultaneous control of current gain and intrinsic resistance allows linear control of FO and provides extension of frequency tuning range. In the proposed circuit all the capacitors are grounded. The use of only grounded capacitors makes the proposed circuit ideal for integrated circuit implementation. The presented active element realized by using BiCMOS technology and the behavior of proposed circuit are discussed in details. The theoretical results are verified by SPICE simulations based on CMOS ON-Semi C5 $0.5 \mu \mathrm{m}$ and bipolar ultra high frequency transistor arrays Intersil HFA 3096 process parameters.
\end{abstract}

K e y w o r d s: electronic control, sinusoidal oscillator, current feedback amplifier (CFA), double current controlled CFA (DCC-CFA)

\section{INTRODUCTION}

Recently, in [1], the fact of plenty available analog building blocks (ABBs) for analog signal processing is discussed. In [1], the review of basic, modified, and novel active elements is also given. In the last years in the literature interesting applications of components mentioned in [1], such as operational transconductance amplifier (OTA) [2,3], current controlled second-generation current conveyor (CCCII) $[4,5]$, dual-X second-generation current conveyor (DXCCII) [6,7], fully-differential secondgeneration current conveyer (FDCCII) [8,9], current feedback amplifier (CFA) [10], current controlled CFA (CCCFA) [11], modified current feedback operational amplifier (MCFOA) [12], current differencing buffered amplifier (CDBA) $[13,14]$, current differencing transconductance amplifier (CDTA) $[15,16]$, current follower transconductance amplifier (CFTA) [17,18], programmable current amplifiers [19,20], adjustable current followers [21], etc, have been published. Many of these components offer features for electronic control and great frequency response. Mentioned elements find wide range of applications in the field of sensor, control, measuring, automotive electronics, acoustic, and high-speed \& radio-communication systems (amplifiers, filters, oscillators, modulators, active rectifiers, etc) [22-28].

The possibilities of electronic tunability of ABBs are today focused to several ways. As an example internal (intrinsic) resistance $R_{\mathrm{X}}$ control by bias current $I_{\mathrm{b}}[5,11$,
29], transconductance $\left(g_{\mathrm{m}}\right)$ control by bias current $I_{\mathrm{b}}$ [30-33], control by one passive element (grounded or floating resistor), so-called single resistance controlled oscillators (SRCO) [34-38] can be mentioned. Some suitable solutions allow replacement of the resistor by FET and easy voltage control of frequency of oscillation (FO) $[35,37]$. Interesting approach based on synthetic negative capacitance control is published in [39]. Switching of working capacitors is also suitable method, if continuous control of FO is not necessary [40]. Another interesting way is the use of current gain control, which is not so common. Several solutions of electronically controllable current conveyors were proposed [41-45] and applied for electronic control of frequency of oscillation $[44,45]$.

Short review of several important previously presented solutions of oscillators with CFAs is summarized below. Siripruchyanun et al [11] proposed oscillator employing two CFAs and two capacitors with $g_{\mathrm{m}}$ and $R_{\mathrm{X}}$ control, but FO tunability has not been verified. Verification was provided by simulation at $f_{0}=820 \mathrm{kHz}$ with total harmonic distortion (THD) $2.7 \%$. In [34], Gupta et al presented SRCO solutions based on two CFA and five passive elements, where one of two capacitors is floating. Tunability range of the verified type was from 45 to $150 \mathrm{kHz}$ with THD $=0.6 \%$. In [35], Gupta et al presented similar types of SRCO oscillators employing two CFAs and 5-6 passive elements. Oscillation frequency is tunable by FET replacement of specific resistor approximately from 230 to $300 \mathrm{kHz}$ with $\mathrm{THD}=1.6 \%$. Lahiri et al proposed several

\footnotetext{
* Department of Radio Electronics, ${ }^{* *}$ Department of Telecommunications, Brno University of Technology, Technická 12,616 00 Brno, Czech Republic, sotner@feec.vutbr.cz *** Department of Electronics and Telecommunication Engineering, Corlu Engineering Faculty, Namik Kemal University, Cerkezkoy Yolu, 3. km, 59860 Corlu, Turkey
} 


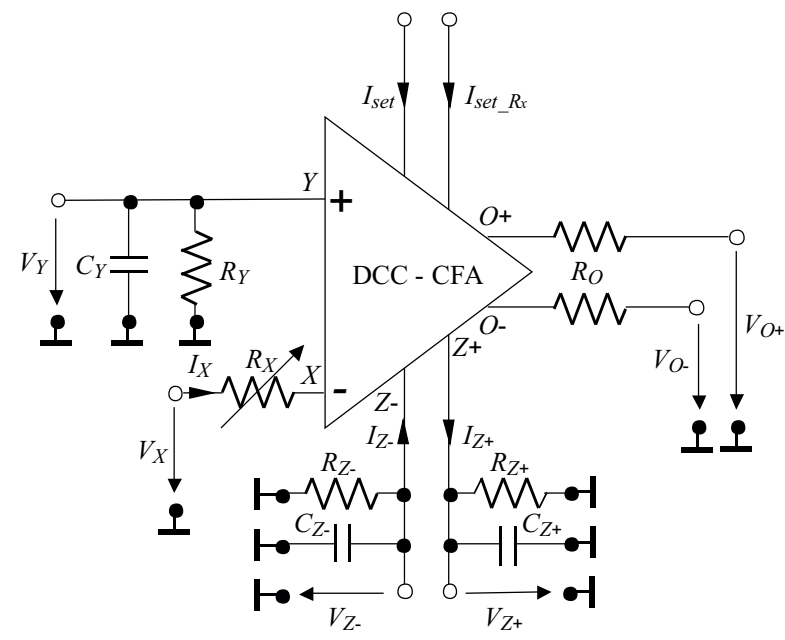

Fig. 1. Circuit symbol of the DCC-CFA including parasitic elements representing small-signal properties

Table 1. Dimensions of CMOS transistors in Figs. 3(a) and (b)

\begin{tabular}{lc}
\hline Transistor & $W / L(\mu \mathrm{m})$ \\
\hline $\mathrm{M}_{1}, \mathrm{M}_{2}, \mathrm{M}_{35}-\mathrm{M}_{44}, \mathrm{M}_{53}, \mathrm{M}_{54}, \mathrm{M}_{60}, \mathrm{M}_{61}, \mathrm{M}_{65}, \mathrm{M}_{66}$ & $20 / 1$ \\
$\mathrm{M}_{3}, \mathrm{M}_{4}, \mathrm{M}_{7}-\mathrm{M}_{25}, \mathrm{M}_{47}, \mathrm{M}_{48}, \mathrm{M}_{51}, \mathrm{M}_{52}, \mathrm{M}_{55}, \mathrm{M}_{56}$ & $40 / 1$ \\
$\mathrm{M}_{5}, \mathrm{M}_{6}, \mathrm{M}_{45}, \mathrm{M}_{46}, \mathrm{M}_{49}, \mathrm{M}_{50}$ & $10 / 1$ \\
$\mathrm{M}_{26}-\mathrm{M}_{34}, \mathrm{M}_{57}-\mathrm{M}_{59}, \mathrm{M}_{62}-\mathrm{M}_{64}$ & $5 / 1$ \\
\hline
\end{tabular}

Table 2. Dimensions of CMOS transistors in Fig. 3(c) (voltage buffer)

\begin{tabular}{lc}
\hline Transistor & $W / L(\mu \mathrm{m})$ \\
\hline $\mathrm{M}_{1}-\mathrm{M}_{3}, \mathrm{M}_{8}, \mathrm{M}_{9}, \mathrm{M}_{12}, \mathrm{M}_{13}$ & $5 / 1$ \\
$\mathrm{M}_{4}-\mathrm{M}_{7}, \mathrm{M}_{10}, \mathrm{M}_{11}, \mathrm{M}_{14}-\mathrm{M}_{17}$ & $10 / 1$ \\
\hline
\end{tabular}

variants of oscillators using two CFAs and 5 passive elements with grounded capacitors [36]. Furthermore, some of them have FO controllable by a single resistor. Verification was provided at $f_{0}=1.3 \mathrm{MHz}$ with $\mathrm{THD}=3 \%$. Bhaskar et al [37] showed several conceptions of SRCO types employing two CFAs with 4-5 passive elements and 2 or 3 capacitors included. Tunability is based on FET replacement of resistor. The change of FO was verified approximately from 3 to $35 \mathrm{kHz}$ with THD between $0.5-2 \%$. Herencsar et al [38] presented SRCO quadrature solutions based on two CFAs and 5 passive elements. Tunability was verified from 100 to $400 \mathrm{kHz}$ with $\mathrm{THD}=0.7 \%$. In [39], Lahiri et alintroduced quadrature realizations using two CFAs and 4 passive elements, where one capacitor is replaced by negative synthetic equivalent for purposes of adjustability. In fact, the circuit contains three active and 6 passive elements. The THD values in both outputs are under $2 \%$. Soliman presented solutions based on 23 CFAs and 4-6 passive elements (all $C$ grounded) [46]. The condition of oscillation (CO) of some of the proposed circuits is quite complicated and the independent control of the FO and CO is not allowed. Several realizations in
[46] of them have quadrature outputs and the feasibility was verified on $f_{0}=159 \mathrm{kHz}$. In [47], Singh et al introduced interesting solutions of SRCOs employing only one CFA and 5 passive elements. Tunability was verified from 5 to $35 \mathrm{kHz}$ and $123-270 \mathrm{kHz}$ with THD $1.4 \%$ and $3 \%$, respectively. Senani et al published SRCO solution based on two CFAs and 5 passive elements with FO adjustability from 50 to $450 \mathrm{kHz}$ [48]. In [49] it is introduced a SRCO, which is designed by Martinez et al, wherein two CFAs and 5 passive elements were used. The circuit is tunable form 40 to $400 \mathrm{kHz}$ with THD $<1 \%$. The SRCO conception presented in [50] by Shen-Iuan et al contains two CFAs and 6 passive elements and it is designed for low frequencies - tunability from $10 \mathrm{~Hz}$ up to $550 \mathrm{~Hz}$. Theoretical work [51] by Celma et al deals with comparison of CFA based oscillators versus classical Op-Amp solutions. The proposed SRCO solution [52] employing one CFA and 5 passive elements is tunable from $330 \mathrm{kHz}$ to $1 \mathrm{MHz}$. Senani et al proposed several SRCO solutions published in [53], where 3 CFAs and 5 passive elements were used. Adjusting of FO is possible from 5 to $15 \mathrm{kHz}$. Some theoretical information about synthesis was given by Gupta et al in [54]. In [55], Abuelmaatti introduced novel oscillator solutions based on partial admittance autonomous networks with 1 and 2 CFAs and verified circuits employ 3 and 4 passive elements, respectively. Unfortunately, equations for FO and $\mathrm{CO}$ are quite complicated. Workability was proved at frequencies around $150 \mathrm{kHz}$. Gunes et al [56] presented interesting approach about several realizations of SRCO oscillators using one CFA and 5 passive elements with favorable and also with complicated design equations. Tunability was verified by $R$ control from $5 \mathrm{kHz}$ to $2 \mathrm{MHz}$ by switching of the working capacitors. Very interesting solution of controllable oscillator was introduced by Bhaskar et al in [57], which is based on one CFA, 5 passive elements and two voltage multipliers for electronic control of FO. The tuning of FO by control voltage was verified from 15 to $73 \mathrm{kHz}$ with THD in range $1.5-1.9 \%$. Summarization of suitable voltage controlled solutions is in [58], where two CFAs are used with two voltage multipliers and 5-6 passive elements. The tunability of the selected circuits was verified from 18 to $130 \mathrm{kHz}$ and for the other variants approximately from 20 to $330 \mathrm{kHz}$. The THD is between $0.8-3.9 \%$. Senani et al [59] also proposed several conceptions employing one CFA and 6 passive elements (3C / 3R), however, tuning of FO is unfortunately not allowed (the circuit is tested at fixed FO of $11.4 \mathrm{kHz}$ ). In both cases the obtained THD is 0.6 and $1.2 \%$.

In general it can be seen that in some of introduced circuits (for example in $[36,37,46]$ ) the CO is very complicated, and overwhelming majority of presented solutions use $R$ control (SRCO) for FO tuning. Hence, in case of floating resistor the adequate voltage control by FET or digital potentiometers can be difficult to implement. Therefore, to eliminate above mentioned disadvantages in the implementation of $R$ control, we present a modified 


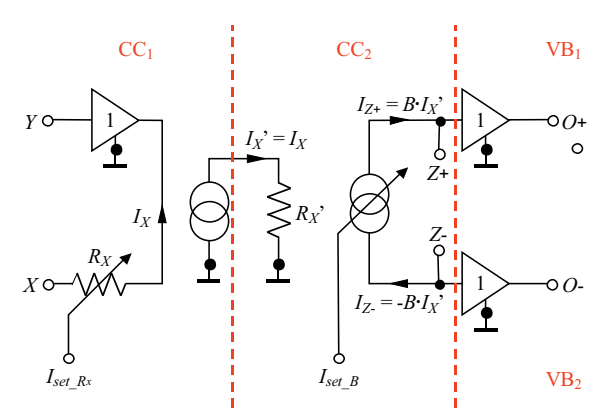

(a)

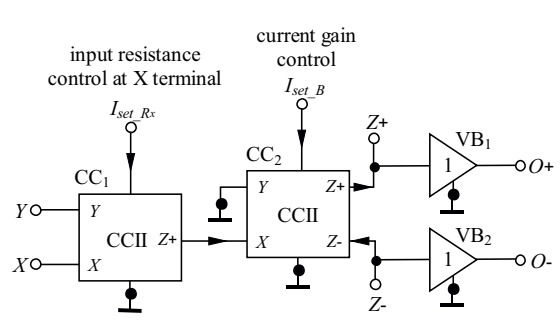

(b)

Fig. 2. (a) - behavioral model and, (b) - block diagram of DCC-CFA

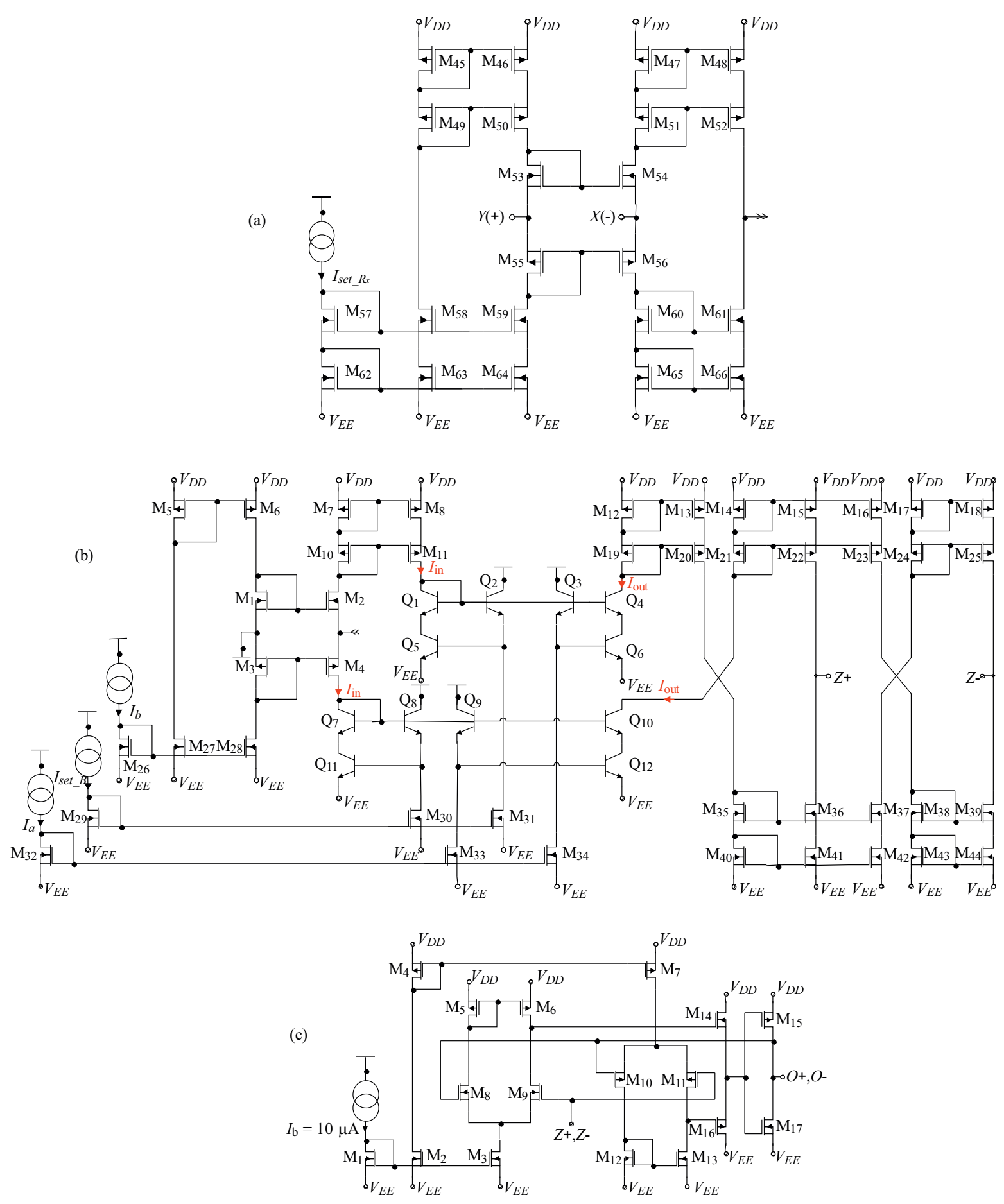

Fig. 3. Conception ofthee internal parts of DCC-CFA: (a) $-\mathrm{CC}_{1},(\mathrm{~b})-\mathrm{CC}_{2},(\mathrm{c})-\mathrm{VB}$ 
ABB of well known CFA so-called Double Current Controlled CFA (DCC-CFA) in this paper. Main advantages of presented active element is the current gain control between ports $\mathrm{X}$ and $\mathrm{Z}$ terminals and control of input (intrinsic) resistance $\left(R_{\mathrm{X}}\right)$ of current input $\mathrm{X}$ terminal without mutually affection that allow simple electronically tunable quadrature oscillator (ETQO) design with fine tuning. Moreover, this paper presents another point of view on frequency of oscillation and condition of oscillation adjusting than use oscillators in many hitherto published CFA based solutions. Hence, combination of two ways of control is possible. Here proposed ETQO provides electronic CO and except "classical" SRCO type of control allows also two another types of electronic control of FO via $R_{\mathrm{X}}\left(I_{\text {set_RX }}\right)$ and current gain $B$ ( $\left.I_{\text {set_B }}\right)$. In addition, simultaneous change of both parameters (their invariant ratio) allows linear FO tuning. Hence, independent control of the $\mathrm{CO}$ and FO without any matching conditions and without changes of any passive elements are very useful features. For wider range of FO tuning and for electronic $\mathrm{CO}$ control via current controlled current gain, a simple implementation of automatic amplitude gain control circuit (AGC) is presented.

\section{DOUBLE CURRENT CONTROLLED CFA (DCC-CFA)}

The CFA device $[1,10,11]$ is equivalent circuit to second-generation current conveyor (CCII), which is followed by voltage buffer. Principle of electronic control of input (intrinsic) resistance (labeled as $R_{\mathrm{X}}$ ) of current input terminal $\mathrm{X}$ is already well known $[11,29]$, where only one CCII and bias control $\left(I_{\mathrm{b}}\right)$ is sufficient $[4,29]$. Implementation of current gain control is more complicated [42]. Previously, in the four terminal floating nullor (FTFN) [60-62] has been implemented such solution, which internal structure contains CCII with special type of controlled current mirror sections, two auxiliary DC currents (gain is given by ratio of these currents), and also standard bias current. Therefore, theoretically it is possible to change current gain and intrinsic resistance $R_{\mathrm{X}}$ in one modified CCII without their mutual affection. However, our further analyses demonstrate that $R_{\mathrm{X}}$ $\left(I_{\mathrm{b}}\right)$ bias current control causes increase of nonlinearity of input dynamical range and current gain interference $\left(R_{\mathrm{X}-I_{\text {set_ }} R \mathrm{X}}\right.$ control affects linearity of $\mathrm{B}$ control by $I_{\text {set_B }}$ ), if current gain (in this paper labeled by symbol $B$ ) is not unity. Therefore, in our design the section for adjusting $R_{\mathrm{X}}\left(I_{\text {set_RX }}\right)$ and gain control $B$ ( $\left.I_{\text {set_B }}\right)$ are separated and all interferences between $R_{\mathrm{X}}$ and $B$ control are eliminated.

Circuit symbol of the DCC-CFA including parasitic elements representing small-signal properties is shown in Fig. 1, which can be described by the following hybrid matrix

$$
\left[\begin{array}{c}
I_{\mathrm{Y}} \\
V_{\mathrm{X}} \\
I_{\mathrm{Z}+} \\
I_{\mathrm{Z}-} \\
V_{\mathrm{O}+} \\
V_{\mathrm{O}-}
\end{array}\right]=\left[\begin{array}{cccccc}
Y_{\mathrm{Y}} & 0 & 0 & 0 & 0 & 0 \\
\alpha & R_{\mathrm{X}} & 0 & 0 & 0 & 0 \\
0 & \beta_{1} B & Y_{\mathrm{Z}+} & 0 & 0 & 0 \\
0 & -\beta_{2} B & 0 & Y_{\mathrm{Z}-} & 0 & 0 \\
0 & 0 & \gamma_{1} & 0 & Z_{\mathrm{O}+} & 0 \\
0 & 0 & \gamma_{2} & 0 & 0 & Z_{\mathrm{O}-}
\end{array}\right]\left[\begin{array}{c}
V_{\mathrm{Y}} \\
I_{\mathrm{X}} \\
V_{\mathrm{Z}+} \\
V_{\mathrm{Z}-} \\
I_{\mathrm{O}+} \\
I_{\mathrm{O}-}
\end{array}\right],
$$

where $Y_{\mathrm{Y}}=s C_{\mathrm{Y}}+1 / R_{\mathrm{Y}}, Y_{\mathrm{Z}+}=s C_{\mathrm{Z}_{+}}+1 / R_{\mathrm{Z}_{+}}$, $Y_{\mathrm{Z}-}=s C_{\mathrm{Z}-}+1 / R_{\mathrm{Z}-}, Z_{\mathrm{O}+}=R_{\mathrm{O}+}, Z_{\mathrm{O}-}=R_{\mathrm{O}-}$ are parallel admittances and resistances at their relevant terminals. The $\alpha$ is voltage tracking error between $\mathrm{Y}$ and $\mathrm{X}$ terminals $(\alpha=1-\varepsilon,|\varepsilon| \ll 1), \beta_{1,2}$ are current tracking errors $(\beta=1-\delta,|\delta| \ll 1)$ between $\mathrm{X}$ and $\mathrm{Z}_{1,2}$ terminals, and $\gamma_{1,2}$ are voltage tracking errors between $\mathrm{Z}$ and O terminals $(\gamma=1-\eta,|\eta| \ll 1)$, respectively.

The behavioral model, the block diagram, and the proposed internal structure of DCC-CFA are shown in Figs. 2 and 3, respectively. The internal structure contains two current conveyors $\left(\mathrm{CC}_{1}\right.$ and $\left.\mathrm{CC}_{2}\right)$ and two voltage buffers (VBs). In Fig. 3(a) the $\mathrm{CC}_{1}$ section is classical CCII with cascoded mirrors [63-65]. The core of the $\mathrm{CC}_{2}$, shown in Fig. 3(b), is based on modified CCII with additional mirrors for current gain control, which was introduced in [60-63]. In Fig. 3(c), the last part of DCC-CFA, the voltage buffer employing two classical transconductance sections is shown $[65,66]$. The supply voltages of DCC-CFA were chosen as $\pm 2.5 \mathrm{~V}$.

The input intrinsic resistance of $\mathrm{CC}_{1}$ stage is given by the following equation

$$
\begin{aligned}
& R_{\mathrm{X}} \approx \frac{1}{g_{\mathrm{m} \_\mathrm{M} 54}+g_{\mathrm{m} \_\mathrm{M} 56}}= \\
& \frac{1}{\sqrt{2 K P_{N}\left(\frac{W_{\mathrm{M} 54}}{L_{\mathrm{M} 54}}\right) I_{\mathrm{set} \_\mathrm{RX}}+\sqrt{2 K P_{P}\left(\frac{W_{\mathrm{M} 56}}{L_{\mathrm{M} 56}}\right) I_{\mathrm{set} \mathrm{RX}}}}},
\end{aligned}
$$

where $W$ and $L$ are the channel width and length, respectively, and $K P=\mu_{0} C_{\mathrm{OX}}\left(\mu_{0}\right.$ is carrier mobility, $C_{\mathrm{OX}}$ is the gate-oxide capacitance per unit area) for the used CMOS ON-Semi C5 $0.5 \mu \mathrm{m}$ technology model (LOT: T22Y_TT, WAF: 3104) [67]. The dimensions of the MOS transistors used in the DCC-CFA implementation are listed in Tab. 1 ( $\mathrm{CC}_{1}$ and $\mathrm{CC}_{2}$ stages $)$ and Tab. 2 (voltage buffer), respectively.

The current gain control of DCC-CFA, which is implemented in the stage $\mathrm{CC}_{2}$ shown in Fig. 3(b), is done by special current mirrors formed by group of transistors $\mathrm{Q}_{1}-\mathrm{Q}_{12}$ for purposes of electronic adjustability. Moreover, in comparison with PNP types of transistors, NPN types have much better properties in particular technology, and therefore, design is done with NPN types only. In the simulations the commercially available models of ultra high frequency transistor arrays Intersil HFA 3096 were used [68]. Applying the translinear principle [20,60,61,69-71] and assuming that all transistors are well matched with the common-emitter current gains 


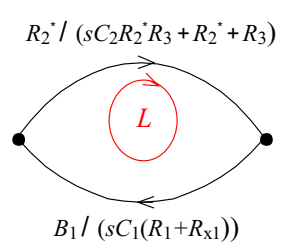

(a)

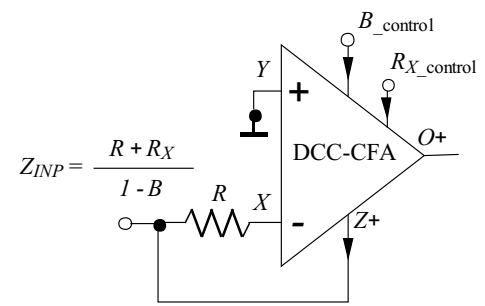

(c)
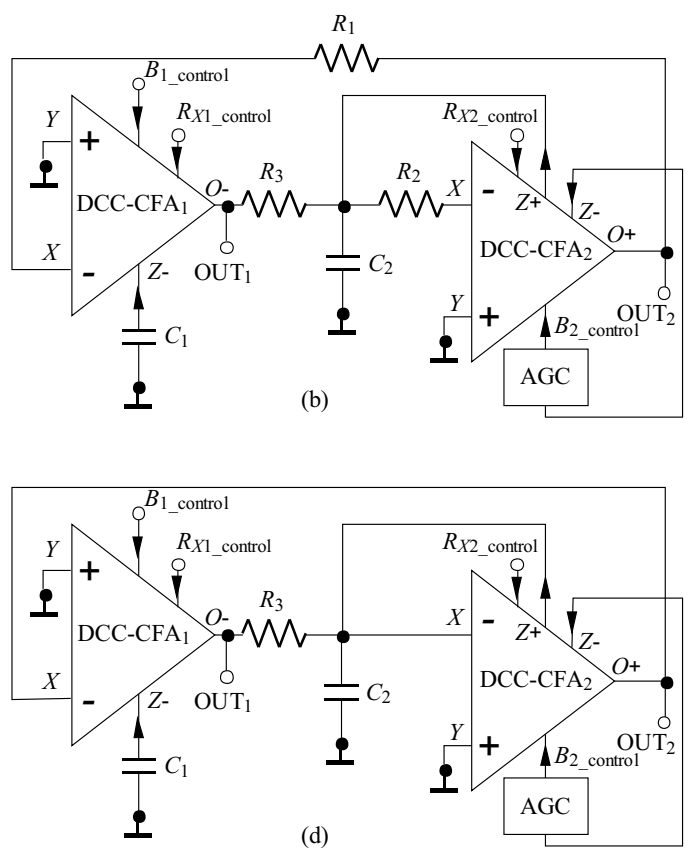

Fig. 4. (a) - signal flow graph of the proposed oscillator, (b) - the proposed oscillator, (c) - controllable negative resistance based on DCC-CFA, (d) - minimal realization of proposed oscillator using intrinsic resistances of current inputs

$h_{21 \mathrm{e}} \gg 1$, then the relationship of the collector currents can be characterized by the following equations

$$
\begin{aligned}
\prod_{n \in C W} I_{n} & =\prod_{n \in C C W} I_{n}, \\
I_{C_{-} Q 5} I_{C_{-} Q 2} & =I_{C_{-} Q 3} I_{C_{-} Q 6}, \\
I_{C_{-} Q 11} I_{C_{-} Q 8} & =I_{C_{-} Q 9} I_{C_{-} Q 12},
\end{aligned}
$$

where CW means clockwise and CCW counter clockwise direction of calculation in translinear approach. In (4) and (5) $I_{C_{-} Q 5}$ and $I_{C_{-} Q 11}$ are input currents of the socalled "gain producing bipolar section" and $I_{C_{-} Q 6}$ and $I_{C_{-} Q 12}$ are the output currents. According to the previous statement, (4) and (5) can be express as

$$
I_{\text {in }} I_{C_{-} Q 2}=I_{C_{-} Q 3} I_{\text {out }}, I_{\text {in }} I_{C_{-} Q 8}=I_{C_{-} Q 9} I_{\text {out }} .
$$

Assuming that $I_{C_{-} Q 2}=I_{C_{-} Q 8}=I_{\text {set_B }}$ and $I_{C_{-} Q 3}=$ $I_{C_{-} Q 9}=I_{\mathrm{a}}$, the current gain can be calculated as follows

$$
B \approx \frac{I_{\text {out }}}{I_{\text {in }}}=\frac{I_{C_{-} Q 8}}{I_{C_{-} Q 9}}=\frac{I_{C_{-} Q 2}}{I_{C_{-} Q 3}}=\frac{I_{\text {set_B }}}{I_{\mathrm{b}}} .
$$

From (7), it is evident that the current gain can be easily controlled by either $I_{\text {set_B }}$ and/or $I_{\mathrm{a}}$.

\section{OSCILLATOR DESIGN WITH TWO WAYS OF FO AND CO TUNING}

The are many approaches leading to synthesis of oscillators in current technical literature[72]. As an example, loop and multi-loop integrator systems, autonomous circuit nodal analysis, or the state variable method can be mentioned $[34,37,46]$. Here proposed quadrature oscillator is based on very common approach employing integrators in the loop. The signal flow graph (SFG) of proposed oscillator and the corresponding circuit employing two DCC-CFAs and five passive elements is shown in Figs. 4(a) and (b), respectively. It is based on loop feedback system with one lossless voltage integrator (DCC-CFA $1, R_{1}$, and $C_{1}$ ) and passive lossy voltage integrator (PLVI), which is formed by $R_{3}$ and $C_{2}$. In addition, the PLVI requires a negative resistance that is realized by another current amplifier included in frame of the DCC-CFA 2 , as it is shown in Fig. 4(c).

The determinant of SFG [73] for the oscillator from Fig. 4(b) is shown in Fig. 4(a) and has a form

$$
\Delta=1-\left[\frac{-B_{1}}{s C_{1}\left(R_{1}-R_{\mathrm{X} 1}\right)} \frac{R_{2}^{*}}{s C_{2} R_{2}^{*} R_{3}+R_{2}^{*}+R_{3}}\right]=0,
$$

where $R_{2}^{*}$ represents a negative resistance given by

$$
R_{2}^{*}=\frac{R_{2}+R_{\mathrm{X} 2}}{1-B_{2}}
$$

By substituting (9) into (8) we obtain the characteristic equation $(\mathrm{CE})$ of the circuit in the following simple form

$$
\begin{aligned}
\mathrm{CE}: & s^{2}+s \frac{R_{3}+\left(R_{2}+R_{\mathrm{X} 2}\right)-R_{3} B_{2}}{R_{2} R_{3} C_{2}} \\
& +\frac{B_{1}}{R_{3} C_{1} C_{2}\left(R_{1}+R_{\mathrm{X} 1}\right)}=0,
\end{aligned}
$$

where the condition of oscillation and the frequency of oscillation are

$$
\begin{array}{ll}
\mathrm{CO}: & B_{2} \geq \frac{R_{3}+\left(R_{2}+R_{\mathrm{X} 2}\right)}{R_{3}}, \\
\mathrm{FO}: & \omega_{0}=\sqrt{\frac{B_{1}}{R_{3} C_{1} C_{2}\left(R_{1}+R_{\mathrm{X} 1}\right)}} .
\end{array}
$$




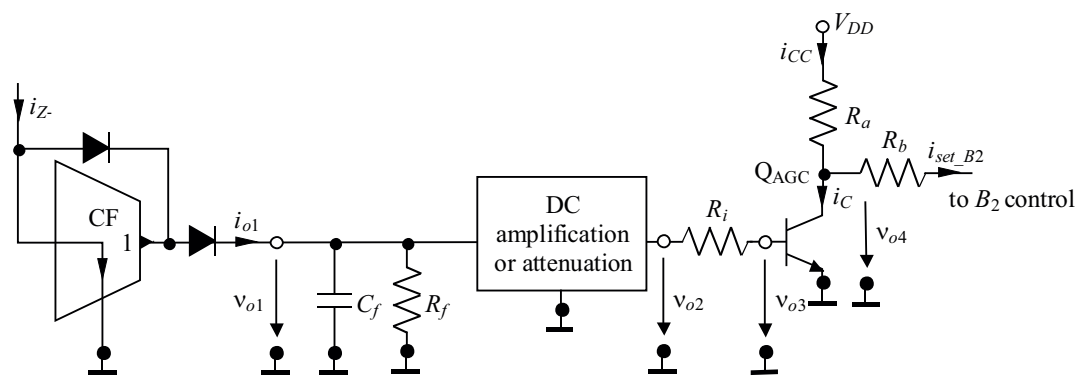

Fig. 5. Detailed AGC circuit

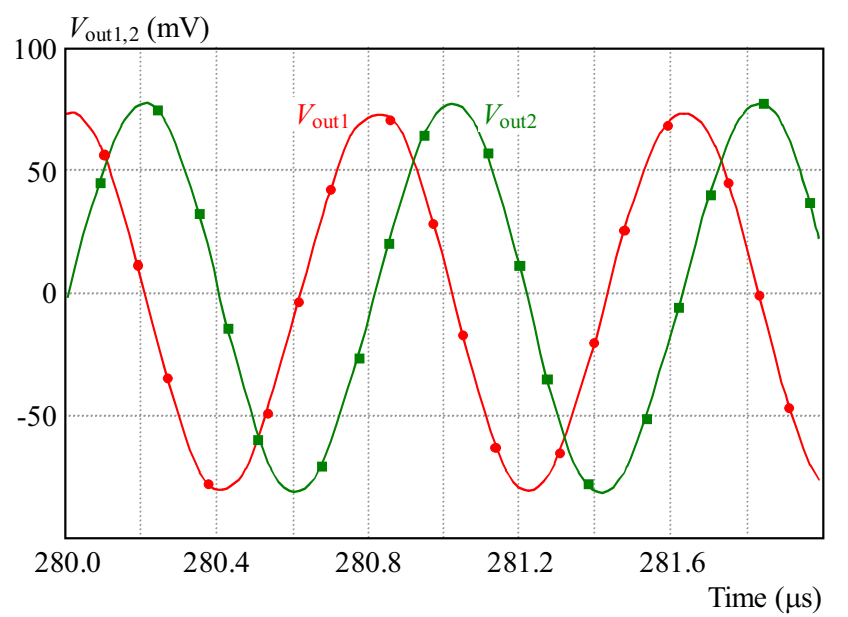

Fig. 6. Stable state output oscillations

From (11) and (12) it can be seen that in ideal case the $\mathrm{CO}$ and FO are independently adjustable by current gains of DCC-CFAs. Moreover, the FO can be adjustable by floating resistor $R_{1}$, therefore, this oscillator can also be added to the group of oscillators referred as SRCO types. Unfortunately, the replacement or adjusting of floating element can be complicated. Therefore, in our case we can also use intrinsic resistance control of DCC-CFA $\left(R_{\mathrm{X}}\right)$, which allows tuning by very simple way. Assuming that the current gain of $\mathrm{DCC}^{-\mathrm{CFA}_{1}}$ is equal to 1 (fixed gain), the FO in (12) turns to

$$
\text { FO : } \quad \omega_{0}=\sqrt{\frac{1}{R_{3} C_{1} C_{2}\left[R_{1}+R_{\mathrm{X}}\left(I_{\text {set_RX }}\right)\right]}} .
$$

The equivalent minimal oscillator circuit is show in Fig. 4(d) in case of only internal intrinsic resistances $R_{\mathrm{X} 1}, R_{\mathrm{X} 2}\left(R_{1}=R_{2}=0\right)$ and one external $R_{3}$ are considered.

The relative sensitivities of the frequency of oscillation (12) on circuit parameters can be calculated as

$$
\begin{gathered}
S_{R_{1}}^{\omega_{0}}=-0.5 \frac{R_{1}}{R_{1}+R_{\mathrm{X} 1}}, \quad S_{R_{\mathrm{X} 1}}^{\omega_{0}}=-0.5 \frac{R_{\mathrm{X} 1}}{R_{1}+R_{\mathrm{X} 1}}, \\
S_{R_{3}, C_{1}, C_{2}}^{\omega_{0}}=-S_{B_{1}}^{\omega_{0}}=-0.5, \quad S_{B_{2}, R_{\mathrm{X} 2}, R_{2}}^{\omega_{0}}=0 .
\end{gathered}
$$

Equation (14) indicates that the $\omega_{0}$ passive and active sensitivities are equal or not higher than 0.5 in absolute value, and hence, the circuit exhibits an attractive sensitivity performance.

\section{SIMULATION RESULTS}

In this Section, results concerning oscillator from Fig. 4(b), ie time domain, tuning properties and quality of produced signal are presented. Input resistances $R_{\mathrm{X} 1,2}$ were set to $760 \Omega\left(I_{\text {set_Rx }}=50 \mu \mathrm{A}\right)$. External resistors have values $200 \Omega$, therefore real values of $\left(R_{1}+R_{\mathrm{X} 1}\right)$ and $\left(R_{2}+R_{\mathrm{X} 2}\right)$ can be considered as $960 \Omega$. The proposed oscillator is also able to operate without external resistors, as it is shown in Fig. 4(d). However, the analyses showed that the solution with external resistors of small values is better in THD. Therefore, the usage of external resistors $R_{1}$ and $R_{2}$ is matter of spectral quality of generated waveform. The current transfer $B_{1}=0.8$ is set by $I_{\text {set_B1 }}=40 \mu \mathrm{A}$. To fulfill the $\mathrm{CO}$ in (11) and to start the oscillation, the $B_{2} \geq 2$ must be satisfied, which corresponds in the ideal case to $I_{\text {set_B2 }} \geq 100 \mu \mathrm{A}$.

Since we expect wider range of electronic tuning of FO, stable output level, and lower THD, a precise automatic amplitude gain control circuit (AGC) implementation (Fig. 4(b)) is necessary. In low-voltage CMOS and BiCMOS technologies there is always problem with linearity and amplitude of output signal, which is quite small (tens - hundreds $\mathrm{mV}$ maximally). The implementation of AGC is quite easy, since the $\mathrm{CO}$ is controlled by $B_{2}$ parameter. Theoretically, the rectified output voltage is able to control $B_{2}$, but here proposed and similar types of oscillators provides output amplitude with several tens or hundreds of $\mathrm{mV}$. Hence, before the rectification a sufficiently larger level amplification (several times) is necessary. Subsequently, the used amplifier before rectification must have great frequency features and also great slew rate. Such conception is better for higher output oscillation level, where pre-amplification (before rectifier) is not necessary. Therefore, we utilized the current-mode rectifier (based on current follower [74]) as it is shown in Fig. 5. We engaged unused (grounded in practice) current output Z- of DCC-CFA 2 in this case. The current follower in Fig. 5 was modeled by the diamond transistor OPA860 [75]. An advantage of this rectifier is in precise rectification suitable for low current amplitudes (tens of $\mu \mathrm{A})$. In the simulations, the BAS70 [76] high speed diode with minimal threshold voltage and short recovery time was used, which provides low output amplitudes.

Figure 6 shows the output oscillation at both outputs for $B_{1}=0.8\left(I_{\text {set_B1 }}=40 \mu \mathrm{A}\right)$. Oscillator pro- 


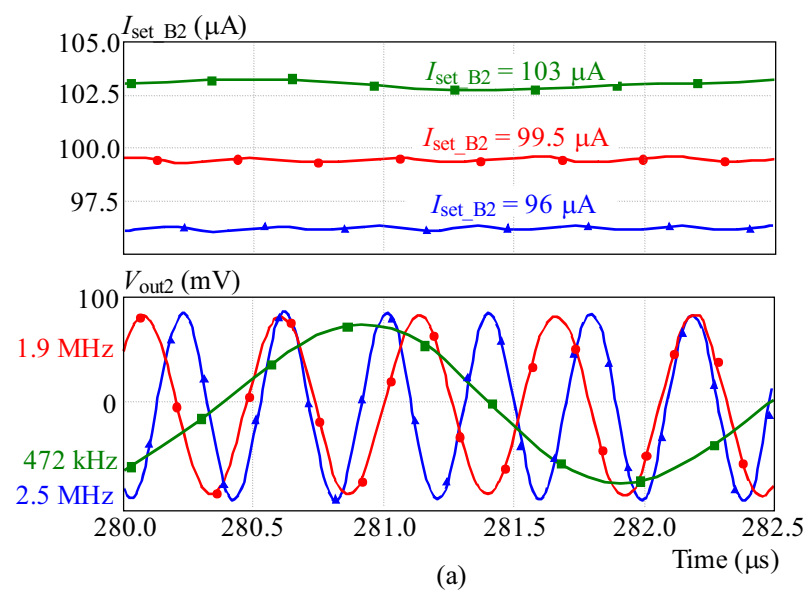

Fig. 7. (a) Tuning process observed on $\mathrm{OUT}_{2}$ and corresponding AGC response, (b) spectrum of $\mathrm{OUT}_{2}$ output oscillations

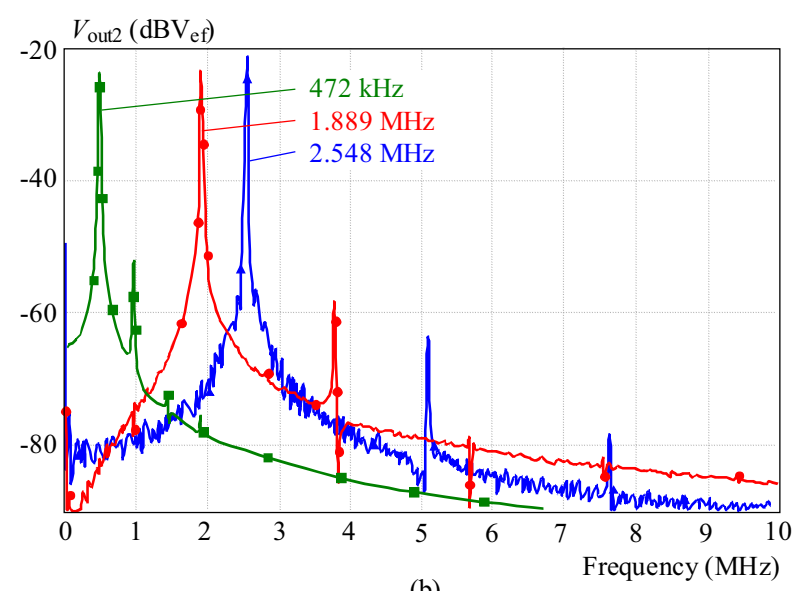

(b)

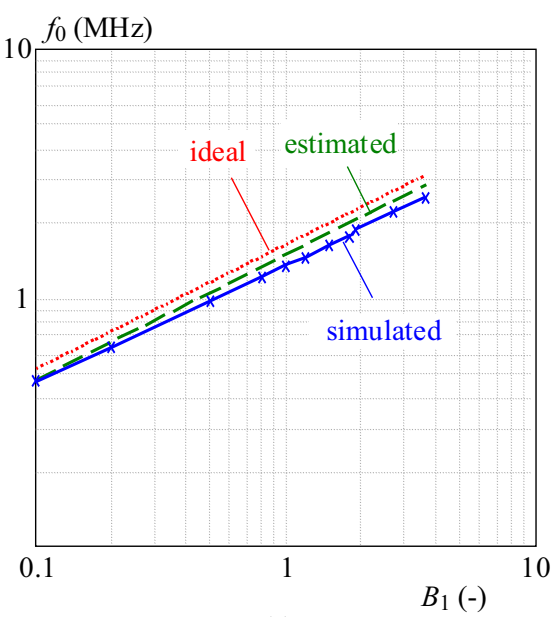

(a)

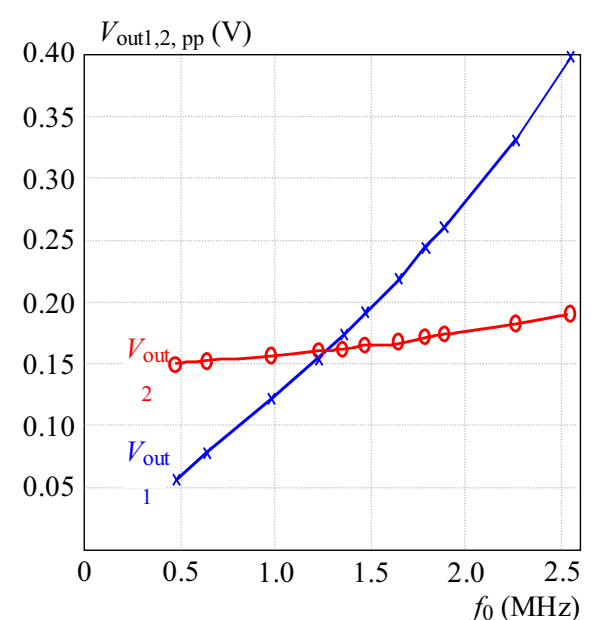

(b)

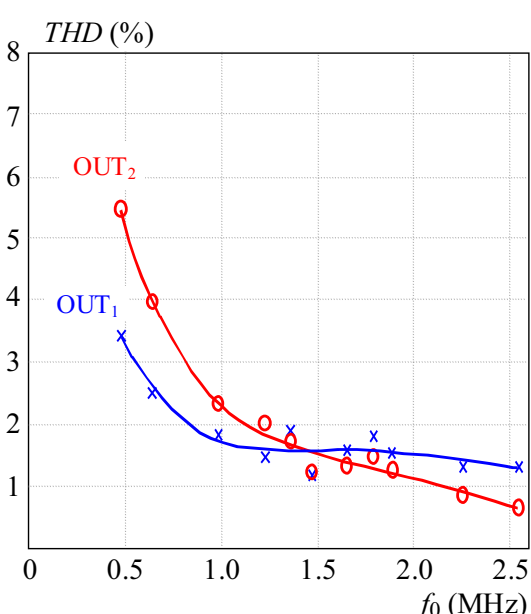

(c)

Fig. 8. Current gain control of oscillation frequency: (a) - dependence of FO on controlled current gain $B_{1}$, (b) - dependence of output amplitudes on frequency of oscillation, (c) - THD versus oscillation frequency

duces quadrature outputs (see SFG in Fig. 4(a) - relation between outputs)s in steady state operation. Simulations provided oscillation frequency $1.23 \mathrm{MHz}$. Theoretical value is $1.45 \mathrm{MHz}$. Considering the parasitic influences of the circuit, the obtained frequency of oscillation is $1.32 \mathrm{MHz}$ for both outputs with amplitudes about $160 \mathrm{mV}$ peak-to-peak.

\subsection{FO control via current gain}

The first way of control the FO of the oscillator from Fig. 4(b) is via current gain $B_{1}\left(I_{\text {set_B1 } 1}\right)$. The output level of $V_{O U T 2}$ achieved values between $150-190 \mathrm{mV}$ peak-topeak, in the tuning range approximately from $470 \mathrm{kHz}$ to $2.5 \mathrm{MHz}$ for $B_{1}$ from 0.1 to 3.6 . Figure 7 shows three output waveforms for different oscillation frequencies together with corresponding responses of AGC $\left(I_{\text {set_B2 }}\right)$ on change of output amplitude and spectrum of $V_{O U T 2}$. The output $V_{O U T 1}$ changed voltage level rapidly from 56 to $400 \mathrm{mV}$, peak-to-peak (in the same frequency range of FO adjusting). The difference between the approximately determined, when small-signal parasitic influences $C_{\mathrm{p}}$ of DCC-CFA are considered and simulated FO is caused by non-ideal properties of active elements used and nonlinearity of $B$ control. Figure 8 shows graphical representations of the obtained results $i e$ dependence of $\mathrm{FO}$ on $B_{1}$, dependence of output level on FO, and THD versus FO, respectively. Obtained results are in good agreement with theory. Better results can be obtained by more careful CO and AGC settings. However, due to complex DCC-CFA transistor model, the optimization of oscillator parameters is time consuming.

\subsection{FO control by intrinsic resistance}

In case of the second possibility of FO control, the FO, given by (13), can be easily controlled by means of control current $I_{\text {set_RX1 }}$ of DCC-CFA 1 . The dependences of FO on $R_{\mathrm{X} 1}$ and dependences of output amplitudes on FO are shown in Fig. 9, respectively. Output level of $V_{\text {OUT2 }}$ is greater than in previous case of control, ie between $160-175 \mathrm{mV}$ peak-to-peak. The output signal level of $V_{\text {OUT1 }}$ is changed in narrower range from 110 to $260 \mathrm{mV}_{\mathrm{P}-\mathrm{P}}$. However, the tunability range is narrower than in previous case and it is approximately from 


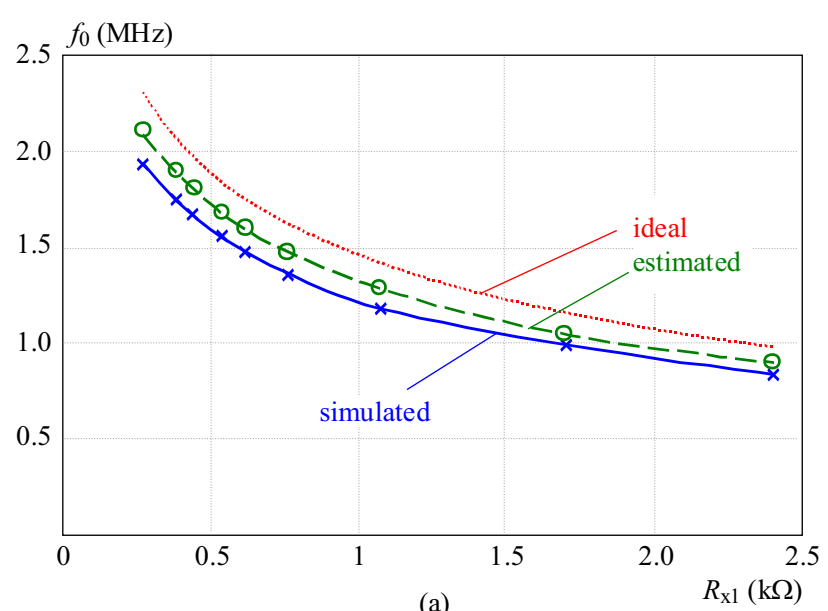

(a)

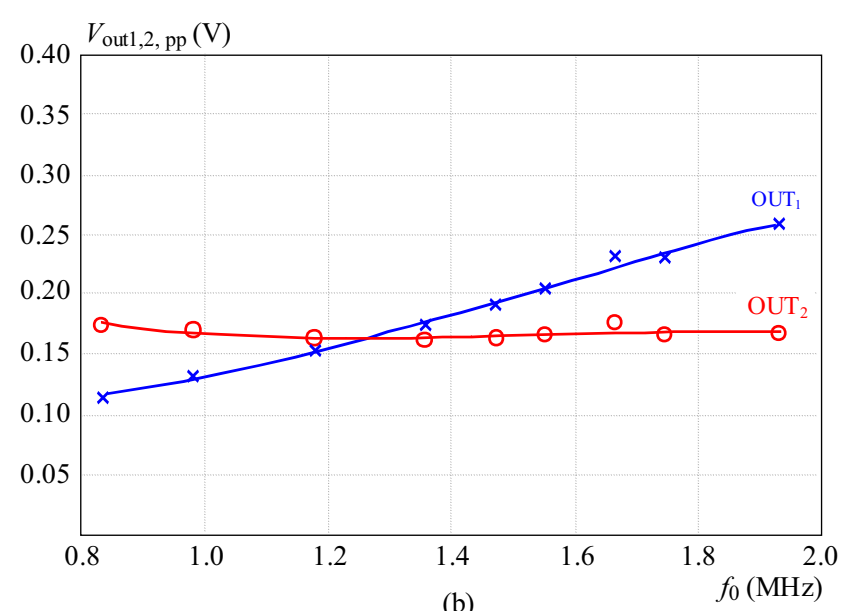

(b)

Fig. 9. Intrinsic resistance control of oscillation frequency: (a) - dependence of frequency of oscillation on intrinsic resistance, (b)dependence of output amplitudes on frequency of oscillation

$830 \mathrm{kHz}$ to $1.93 \mathrm{MHz}$. The THD values are close to the THD of the first type of adjusting.

\section{DISCUSSION}

First type of electronic control of frequency of oscillation via $B_{1}$ is suitable for wider range of tuning. Results show that the frequency is tunable approximately from $470 \mathrm{kHz}$ to $2.5 \mathrm{MHz}$. The AGC system defends oscillator against large fluctuations or outages of output amplitudes, however, in direction to higher frequencies it still brings small $(40 \mathrm{mV})$ change of $V_{\text {OUT2 }}$ amplitude. The second variant of electronic control by intrinsic resistance $R_{\mathrm{X}}$ is suitable for shorter range of adjusting with better stability of the output level $\left(V_{\text {OUT2 }}\right)$ in the range of interest. In this case the variance of $V_{\text {OUT2 }}$ is only about $15 \mathrm{mV}$ and, in comparison to $B_{1}$ control of FO, the range of oscillation frequency adjusting is approximately two times narrower, ie from $830 \mathrm{kHz}$ to $1.93 \mathrm{MHz}$. This weakness is given by the constraining technological limits of $R_{\mathrm{X}}$ caused by smaller and restricted changes of $R_{\mathrm{X}}$ (range between saturation and linear region of transistors). The effect of $R_{\mathrm{X}}$ on frequency of oscillation is also determined by sensitivity of $R_{\mathrm{X}}$ on FO that is decreasing, if $R_{1} \gg R_{\mathrm{X} 1}$. In both cases the THD is comparable. If simultaneous adjusting of both parameters in Fig. 4(b) ( $B_{1}$ and also $R_{\mathrm{X}}$ ) is applied, it allows spreading of FO range from $283 \mathrm{kHz}\left(I_{\text {set_B1 }}=5 \mu \mathrm{A}, I_{\text {set_RX }}=5 \mu \mathrm{A}\right)$ to $3.48 \mathrm{MHz}\left(I_{\text {set_B1 }}=200 \mu \mathrm{A}, I_{\text {set_Rx }}=400 \mu \mathrm{A}\right)$, and also linear control of FO (if $B_{1}$ and $\left(R_{1}+R_{\mathrm{X} 1}\right)$ ratio keeps preserved).

Analyzing of (12) from Fig. 4(a) and assuming that $C_{1}=C_{2}=C$, the relation between $V_{\text {OUT2 }}$ and $V_{\text {OUT1 }}$ can be given as

$$
V_{\mathrm{OUT} 1}=V_{\mathrm{OUT} 2} \sqrt{B_{1} \frac{R_{3}}{\left(R_{1}+R_{\mathrm{X} 1}\right)}} .
$$

From (15) it is evident that the output voltage level at $\mathrm{OUT}_{1}\left(V_{\mathrm{OUT} 1}\right)$ is dependent on current gain $B_{1}$, which affects the frequency of oscillation. Moreover, the $V_{\text {OUT1 }}$ is also dependent on $\left(R_{1}+R_{\mathrm{X} 1}\right)$, which appears in $\mathrm{DCC}_{-\mathrm{CFA}}$ based lossless integrator unit and both amplitudes ( $V_{O U T 1}$ and $V_{O U T 2}$ ) are unchangeable (or even equal) during the tuning process if invariant ratio of $B_{1}$ and $\left(R_{1}+R_{\mathrm{X} 1}\right)$ is ensured.

\section{CONCLUSION}

In this paper, easy construction of oscillator with mutually independent control of frequency of oscillation and condition of oscillation was demonstrated. Used approach employs standard loop integrator system with controllable negative resistance based double current controlled CFAs. Advantage of introduced specific modification of CFA in signal processing and electronically tunable applications is clear. Proposed ABB allows current gain and internal (intrinsic) resistance control simultaneously. The proposed oscillator in minimal configuration employs three passive elements and it is tunable by current gain $(B)$ or by internal resistance $\left(R_{\mathrm{X}}\right)$, both controlled by auxiliary DC control currents. The full realization of the oscillator with five passive elements belongs to the category of the so-called SRCO types, because FO control is also allowed by external floating resistor $R_{1}$. The tunability range was verified by simulations from $283 \mathrm{kHz}$ to $3.48 \mathrm{MHz}$ by both ways of the electronic FO control simultaneously. For stable output voltage levels and wider range of frequency tuning, a precise AGC system was designed. Amplitudes of output oscillations and total harmonic distortion are adequate to the used low voltage technology, low dynamic ranges of used active elements and quality of AGC circuit. Advantages of proposed solution are the following: sufficient range of tunability with possible extension by two types of FO control, possibility of linear control of FO, possibility of operation with equal amplitudes, grounded capacitors, easy final construction, and low sensitivities on passive components. Theoretical study was confirmed by detailed SPICE simulations. 


\section{Acknowledgments}

Research described in the paper was supported by Czech Science Foundation projects under No. 102/11 /P489 and No. 102/09/1681. The support of the project CZ.1.07/2.3.00/20.0007 WICOMT, financed from the operational program Education for competitiveness, is gratefully acknowledged. The described research was performed in laboratories supported by the SIX project; the registration number CZ.1.05/2.1.00/03.0072, the operational program Research and Development for Innovation. Dr. Norbert Herencsár was supported by the project CZ.1.07/2.3.00/30.0039 of Brno University of Technology.

Part of this work was done while Ms. Aslihan Kartci was on Erasmus training mobility at the Brno University of Technology, Czech Republic.

\section{REFERENCES}

[1] BIOLEK, D.-SENANI, R.-BIOLKOVA, V.-KOLKA, Z. : Active Elements for Analog Signal Processing: Classification, Review, and New Proposals.

[2] GEIGER, R. L.-SANCHEZ-SINENCIO, E. : Active Filter Design using Operational Transconductance Amplifiers: A Tutorial, IEEE Circuits and Devices Magazine 1 (1985), 20-32.

[3] BIOLEK, D.-BIOLKOVA, V.-KOLKA, Z.: Universal Current-Mode OTA-C KHN Biquad.

[4] FABRE, A.-SAAID, O.-WIEST, F.-BOUCHERON, C.: High Frequency Applications Based on a New Current Controlled Conveyor.

[5] TANGSRIRAT, W.: Current-Tunable Current-Mode Multifunctional Filter Based on Dual-Output Current-Controlled Conveyors, AEU - International Journal of Electronics and Communications 61 No. 8 (2007), 528-533, doi:10.1016/j.aeue.2006.09.005.

[6] ZEKI, A.-TOKER, A. : The Dual-X Current Conveyor (DXCCII): A New Active Device for Tunable Continuous-Time Filters, International Journal of Electronics 89 (2002), 913-923.

[7] KACAR, F.-METIN, B.-KUNTMAN, H.: A new CMOS Dual-X Second-Generation Current Conveyor (DXCCII) with an FDNR Circuit Application, AEU - International Journal of Electronics and Communications (2009), DOI: $10.1016 /$ j.aeue.2009.05.007.

[8] SOLIMAN, A. M.: New Fully-Differential CMOS Second-Generation Current Conveyer, ETRI Journal 28 No. 4 (2006), 495-501.

[9] METin, B.-HERENCSAR, N.-PAL, K.: Supplementary First-Order All-Pass Filters with Two Grounded Passive Elements using FDCCII, Radioengineering 20 No. 2 (2011), 433-437.

[10] SVOBODA, J. A.-McGORY, L.-WEBB, S. : Applications of a Commercially Available Current Conveyor, Int. Journal of Electronics 70 No. 1 (1991), 159-164.

[11] SIRIPRUCHYANUN, M.-CHANAPROMMA, C.-SILAPAN, P.-JAIKLA, W. : BiCMOS Current-Controlled Current Feedback Amplifier (CC-CFA) and its Applications, WSEAS Transactions on Electronics 6 No. 5 (2008), 203-219.

[12] YUCE, E.-MINAEI, S.: A Modified CFOA and its Applications to Simulated Inductors, Capacitance Multipliers, and Analog Filters, IEEE Transaction on Circuits and Systems-I 55 No. 1 (2008), 266-275.

[13] ACAR, C.-OZOGUZ, S.: A new Versatile Building Block: Current Differencing Buffered Amplifier, Microelectronics Journal 30 (1999), 157-160.
[14] KESKIN, A. U.: A Four Quadrant Analog Multiplier Employing Single CDBA, Analog Integrated Circuits and Signal Processing 40 (2004), 99-101.

[15] BIOLEK, D. : CDTA - Building Block for Current-Mode Analog Signal Processing, In Proceedings of the 16th European Conference on Circuit Theory and Design (ECCTD 2003), Krakow, Poland, 2003, pp. 397-400.

16] KESKIN, A. U.-BIOLEK, D.-HANCIOGLU, E.-BIOLKOVA, V.: Current-Mode KHN Filter Employing Current Differencing Transconductance Amplifiers, AEU - Int. J. Electronics and Communications 60 No. 6 (2006), 443-446, DOI: 10.1016/j.aeue.2005.09.003

17] HERENCSAR, N.-KOTON, J.-VRBA, K. : Realization of Current-Mode KHN-Equivalent Biquad using Current Follower Transconductance Amplifiers (CFTAs), IEICE Transaction on Fundamentals E93-A No. 10 (2010), 1816-1819.

[18] HERENCSAR, N.-VRBA, K.-KOTON, J.-LAHIRI, A. : Realisations of Single-Resistance-Controlled Quadrature Oscillators using Generalised Current Follower Transconductance Amplifier and Unity-Gain Voltage-Follower, International Journal of Electronics 97 No. 8 (2010), 897-906.

[19] KOTON, J.-VRBA, K.-HERENCSAR, N. : Tuneable Filter using Voltage Conveyors and Current Active Elements, International Journal of Electronics 96 No. 8 (2009), 787-794.

[20] HERENCSAR, N.-LAHIRI, A.-VRBA, K.-KOTON, J. : An Electronically Tunable Current-Mode Quadrature Oscillator using PCAs, International Journal of Electronics 99 No. 5 (2012), 609-621.

[21] JERABEK, J.-VRBA, K.: Fully Differential Universal Filter with Differential and Adjustable Current Followers and Transconductance Amplifiers, In Proceeding of the 33rd International Conference on Telecommunications and Signal Processing - TSP10, Baden near Vienna, Austria, 2010, pp. 5-9.

[22] VAINIO, O.-OVASKA, S. J.: A Class of Predictive Analog Filters for Sensor Signal Processing and Control Instrumentation, IEEE Transactions on Industrial Electronics 44 No. 4 (1997), 565-578.

[23] SAMITIER, J.-PUIG-VIDAI, M.-BOTA, S. A.-RUBIO, C.-SISKOS, S. K.-LAOPOULOS, T. : A Current-Mode Interface Circuit for a Piezoresistive Pressure Sensor, IEEE Transactions on Instrumentation and Measurement 47 No. 3 (1998), 708-710.

[24] FERRI, G.-GUERRINI, N. C.: Low-Voltage Low-Power CMOS Current Conveyors, Kluwer Acad. Publ., London, 2003.

[25] UYGUR, A.-KUNTMAN, H.: Seventh-Order Elliptic Video Filter with $0.1 \mathrm{~dB}$ Pass Band Ripple Employing CMOS CDTAs, AEU - International Journal of Electronics and Communications 61 No. 5 (2007), 320-328.

[26] LO, T. Y.-KAO, C. S.-HUNG, C. C. : A Gm-C Continuous-Time Analog Filter for IEEE $802.11 \mathrm{a} / \mathrm{b} / \mathrm{g} / \mathrm{n}$ Wireless LANs, Analog Integrated Circuits and Signal Processing 58 No. 3 (2009), 197-204.

[27] FABRE, A.-SAAID, O.-WIEST, F.-BOUCHERON, C. : Low Power Current-Mode Second-Order Bandpass IF Filter, IEEE Transactions on Circuits and Systems-II 44 No. 6 (1997), 436-446.

[28] RUDELL, J. C.-OU, J. J.-CHO, T. B.-CHIEN, G.-BRIANTI, F.-WELDON, J. A.-GREY, P.: A 1.9-GHz WideBand IF Double Conversion CMOS Receiver for Cordless Telephone Applications, IEEE Journal of Solid-State Circuits 32 No. 12 (1997), 2071-2088.

29] HORNG, J. W.: A Sinusoidal Oscillator using Current-Controlled Current Conveyors, Int. Journal of Electronics $\mathbf{8 8}$ No. 6 (2001), 659-664, DOI: 10.1080/00207210110044369.

[30] LAHIRI, A. : Explicit-Current-Output Quadrature Oscillator using Second-Generation Current Conveyor Transconductance Amplifier, Radioengineering 18 No. 4 522-526 (2009). 
[31] HORNG, J. W.-LEE, H.-WU, J.: Electronically Tunable Third-Order Quadrature Oscillator using CDTAs, Radioengineering 19 No. 2 (2010), 326-330.

[32] HERENCSAR, N.-KOTON, J.-VRBA, K.-LATTENBERG, I. : New Voltage-Mode Universal Filter and Sinusoidal Oscillator using Only Single DBTA, International Journal of Electronics 97 No. 4 (2010), 365-379, DOI: $10.1080 / 00207210903325229$.

[33] SOTNER, R.-JERABEK, J.-PETRZELA, J.-DOSTAL, T.-VRBA, K. : Electronically Tunable Simple Oscillator based on Single-Output and Multiple-Output Transconductor, IEICE Electronics Express 6 No. 20 (2009), s 1476-1482, DOI: 10.1587/elex.6.1476.

[34] GUPTA, S. S.-SHARMA, R. K.-BHASKAR, D. R.-SENANI, R.: Sinusoidal Oscillators with Explicit Current Output Employing Current-Feedback op-amps, International Journal of Circuit Theory and Applications 38 No. 2 (2010), 131-147, DOI: 10.1002/cta.531.

[35] GUPTA, S. S.-BHASKAR, D. R.-SENANI, R. : New Voltage Controlled Oscillators using CFOAs, AEU - International Journal of Electronics and Communications 63 No. 3 (2009), 209-217, DOI:10.1016/j.aeue.2008.01.002.

[36] LAHIRI, A.-JAIKLA, W.-SIRIPRUCHYANUN, M. : Explicit-Current-Output Second-Order Sinusoidal Oscillators using Two CFOAs and Grounded Capacitors, AEU - International Journal of Electronics and Communications 65 No. 7 (2011), 669-672, DOI: $10.1016 /$ j.aeue.2010.09.003.

[37] BHASKAR, D. R.-SENANI, R.: New CFOA-Based Single-Element-Controlled Sinusoidal Oscillators, IEEE Transaction on Instrumentation and Measurement 55 No. 6 (2006), 2014-2021, DOI:10.1109/TIM.2006.884139.

[38] HERENCSAR, N.-LAHIRI, A.-KOTON, J.-VRBA, K. : VM and CM Quadrature Sinusoidal Oscillators using Commercially Available Active Devices, In Proceedings of International Conference on Applied Electronics 2010, Pilsen, Czech Republic, 2010, pp. 125-128.

[39] LAHIRI, A.-GUPTA, M. : Realizations of Grounded Negative Capacitance using CFOAs, Circuits, Systems and Signal Processing 30 No. 1 (2011), 134-155,

DOI: $10.1007 / \mathrm{s} 00034-010-9215-3$.

[40] LAHIRI, A. : Current-Mode Variable Frequency Quadrature Sinusoidal Oscillator using Two CCs and Four Passive Components Including Grounded Capacitors, Analog Integrated Circuits and Signal Processing 68 No. 1 (2011), 129-131, DOI: 10.1007/s10470-010-9571-8.

[41] JERABEK, J.-SOTNER, R.-VRBA, K. : Fully-Differential Current Amplifier and its Application to Universal and Adjustable Filter, In Proceedings of International Conference on Applied Electronics 2010, Pilsen, Czech Republic, 2010, pp. 141-144.

[42] MINAEI, S.-SAYIN, O. K.-KUNTMAN, H.: A New CMOS Electronically Tunable Current Conveyor and its Application to Current-Mode Filters, IEEE Transaction on Circuits and Systems-I 53 No. 7 (2006), 1448-1457, DOI: $10.1109 /$ TCSI.2006.875184.

[43] MARCELLIS, A.-FERRI, G.-GUERRINI, N. C.-SCOTTI, G.-STORNELLI, V.-TRIFILETTI, A.: The VGC-CCII: a Novel Building Block and its Application to Capacitance Multiplication, Analog Integrated Circuits and Signal Processing 58 No. 1 (2009), 55-59, DOI: 10.1007/s10470-008-9213-6.

[44] SOTNER, R.-HRUBOS, Z.-SLEZAK, J.-DOSTAL, T. : Simply Adjustable Sinusoidal Oscillator based on Negative Three-Port Current Conveyors, Radioengineering 19 No. 3 (2010), 446-453.

[45] SOTNER, R.-SEVCIK, B.-SLEZAK, J.-PETRZELA, J.BRANCIK, L. : Sinusoidal Oscillator based on Adjustable Current Amplifier and Diamond Transistors with Buffers, Przegląd Elektrotechniczny (Electrical Review) 87 No. 1 (2011), 266-270.
[46] SOLIMAN, A. M.: Current Feedback Operational Amplifier Based Oscillators, Analog Integrated Circuits and Signal Processing 23 No. 1 (2000), 45-55, DOI: 10.1023/A:1008391606459.

47] SINGH, V. K.-SHARMA, R. K.-SINGH, A. K.-BHASKAR, D. R.-SENANI, R. : Two New Canonic Single-CFOA Oscillators with Single Resistor Controls, IEEE Transaction on Circuits and Systems-II 52 No. 12 860-864 (2005), DOI: 10.1109/TCSII.2005.853964.

48] SENANI, R.-SINGH, V. K.: Novel Single-Resistance-Controlled Oscillator Configuration using Current Feedback Amplifiers, IEEE Transactions on Circuits and Systems-I 43 No. 8 (1996), 698-700, DOI: 10.1109/81.526688.

[49] MARTineZ, P. A.-SABADELL, J.-ALDEA, C. : Grounded Resistor Controlled Sinusoidal Oscillator using CFOAs, Electronics Letters 33 No. 5 (1997), 346-348, DOI: $10.1049 / \mathrm{el}: 19970229$.

[50] SHEN-IUAN, L.-JIANN-HORNG, T. : Single-Resistance-Controlled Sinusoidal Oscillator using Current-Feedback-Amplifiers, International Journal of Electronics 80 No. 5 (1996), 661-664, DOI: $10.1080 / 002072196137101$.

51] Celma, S.-CARlosena, A.-Martinez, P. A.: HighQuality Sinusoidal Oscillator using Current Feedback Amplifiers, In Instrumentation and Measurement Technology Conference - IMTC93, 1993, pp. 741-744, DOI: 10.1109/IMTC.1993.382545.

52] Celma, M.-MARTinez, P. A.-SABAdell, J.: On the Design of CFA-Based Sinusoidal Oscillators, In Proceedings of the 20th International Conference on Microelectronics MIEL95, 1995, pp. 731-736, DOI: 10.1109/ICMEL.1995.500958.

[53] SENANI, R.-GUPTA, S. S. : Synthesis of Single-ResistanceControlled Oscillators using CFOAs: Simple State-Variable Approach, IEE Proceedings on Circuits Devices and Systems 144 No. 2 (1997), 104-106, DOI: 10.1049/ip-cds:19971006.

[54] GUPTA, S. S.-SENANI, R. : State Variable Synthesis of Single Resistance Controlled Grounded Capacitor Oscillators using only Two CFOAs, IEE Proceedings on Circuits, Devices and Systems 145 No. 2 (1998), 135-138, DOI: $10.1049 /$ ip-cds:19981667.

[55] ABUelmaAtTi, M. T.: New Two CFOA-Based Sinusoidal RC Oscillator with Buffered Outlet, Analog Integrated Circuits and Signal Processing 66 No. 3 (2011), 475-482, DOI: 10.1007/s10470-010-9582-5.

56] GUNES, E. O.-TOKER, A. : On the Realization of Oscillators using State Equations, AEU - International Journal of Electronics and Communications 56 No. 5 (2002), 317-326, DOI: 10.1078/1434-8411-54100119.

57] BHASKAR, D. R.-SENANI, R.-SINGH, A. K.-GUPTA, S. S. : Two Simple Analog Multiplier Based Linear VCOs using Single Current Feedback op-amp, Circuit and Systems 1 No. 1 (2010), 1-4, DOI: 10.4236/cs.2010.11001.

58] BHASKAR, D. R.-SENANI, R.-SINGH, A. K. : Linear Sinusoidal VCOs: New Configurations using Current-Feedback op-amps, Int. Journal of Electronics 97 No. 3 (2010), 263-272, DOI: $10.1080 / 00207210903286173$.

59] SENANI, R.-SHARMA, R. K.: Explicit-Current-Output Sinusoidal Oscillators Employing Only a Single Current-Feedback op-amp, IEICE Electronics Express 2 No. 1 (2004), 14-18, DOI: 10.1587/elex.2.14.

[60] TANGSRIRAT, W.-UNHAVANICH, S.-DAMAWIPATA, T. : FTFN with Variable Current Gain, In Proceedings of the 10th International Conference on Electrical and Electronic Technology - TENCON01, 2001, pp. 209-212, DOI: $10.1109 /$ TENCON.2001.949582.

61] TANGSRIRAT, W.: Electronically Tunable Multi-Terminal Floating Nullor and its Application, Radioengineering 17 No. 4 (2008), 3-7. 
[62] KUMngERN, M.-CHANWUtiUM, J.-DEJHAN, K. : Electronically Tunable Multiphase Sinusoidal Oscillator using Translinear Current Conveyors, Analog Integrated Circuits and Signal Processing 65 No. 2 (2010), 327-334.

[63] TOUMAzOU, C.-LIDGEY, F. J.-HAIGH, D. G. : Analogue IC design: The current mode approach, Peter Peregrinus Ltd, London, 1990.

[64] ELDBIB, I, MUSIL, V.: Self-Cascoded Current Controlled CCII Based-Tunable Band Pass Filter, In Proceedings of the 18th International Conference Radioelektronika 2008, 2008, pp. 1-4, DOI: 10.1109/RADIOELEK.2008.4542706.

[65] BAKER, J.: CMOS Circuit Design, Layout and Simulation, IEEE Press Series on Microelectronic Systems, 2005.

[66] PROKOP, R.: Modular Approach to Design of Modern Analog Devices in CMOS Technology, 2009, PhD thesis, Dept. of Microelectronics FEEC BUT Brno, Czech Republic.

[67] The MOSIS Service, ON-Semi C5 $0.5 \mu \mathrm{m}$ Wafer Electrical Test Data and SPICE Model Parameters, available on www [online 16.4.2011]: http://www.mosis.com/Technical/Testdata/ ami_c5n_corner_bsim3.txt.

[68] Linear Technology, Ultra high frequency transistor arrays HFA 3046/3096/3127/3128, datasheet, 1-13 (2005), available on www [online 16.4.2011]: http:// www.intersil.com/products/deviceinfo.asp?pn=HFA3096

[69] GILBERT, B.: Translinear Circuits: a Historical Overview, Analog Integrated Circuits and Signal Processing 9 No. 2 (1996), 95-118, DOI: 10.1007/BF00166408.

[70] BRADLEY, A.: MOS Translinear Principle for All Inversion Levels, IEEE Transaction on Circuits and Systems-II 55 No. 2 (2008), 121-125, DOI: 10.1109/TCSII.2007.910904.

[71] SHU-XIANGS.-GUO-PING, Y.-HUA, C.: A New CMOS Electronically Tunable Current Conveyor Based on Translinear Circuits, In Proceeding of 7th International Conference on ASIC - ASICON07, 2007, pp. 569-572, DOI: 10.1109/ICASIC.2007.4415694.

[72] CHEN, W. K. : The Circuits and Filters Handbook, CRC Press, Florida, 1995.

[73] MASON, S. J.: Feedback Theory: Further Properties of Signal Flow Graphs, Proc. IRE 44 No. 7 (1956), 920-926.

[74] TANGSRIRAT, W.: Current Limiters using Single Current Follower and Applications to Precision Rectifiers, Indian Journal of Pure and Applied Physics 49 No. 4 (2011), 284-287.

[75] Texas Instruments Wide-Bandwidth Operational Transconductance Amplifier and Buffer OPA 860, Datasheet, 1-3, 2008, available on www [online: 16.4.2011]:

http://focus.ti.com/docs/prod/folders/print/opa860.html.

[76] ST Microelectronics, BAS 70 - Small Signal Schottky Diodes, Datasheet, 1-4, 2001, available on www [online 16.4.2011]: http://www.datasheetcatalog.com/datasheets_pdf/ B/A/S/7/BAS70-04.shtml.

Received 8 January 2012

Roman Šotner was born in Znojmo, Czech Republic, in 1983. He received the MSc and $\mathrm{PhD}$ degrees from Brno University of Technology, Czech Republic, in 2008 and 2012, respectively. Currently, he is a technical worker at the Department of Radio electronics, Faculty of Electrical Engineering and Communication, Brno University of Technology, Brno, Czech Republic. His interests are analogue circuits (active filters, oscillators, audio, etc), circuits in the current mode, circuits with direct electronic controlling possibilities especially and computer simulation.
Norbert Herencsár received $\mathrm{MSc}$ and $\mathrm{PhD}$ degrees in Electronics, Communication and Teleinformatics from Brno University of Technology, Czech Republic, in 2006 and 2010, respectively. Currently, he is an Assistant Professor at the Department of Telecommunications, Faculty of Electrical Engineering and Communication, Brno University of Technology, Brno, Czech Republic. From September 2009 through February 2010 he was an Erasmus exchange student with the Department of Electrical and Electronic Engineering, Bogazici University, Istanbul, Turkey. His research interests include analog filters, current-mode circuits, tunable frequency filter design methods, and oscillators. He is an author or co-author of about 75 research articles published in international journals or conference proceedings. Dr. Herencsár is a Member of IEEE, ACEEE, IAENG, and Senior Member of IACSIT.

Jan Jeřábek received the $\mathrm{BSc}, \mathrm{MSc}$ and $\mathrm{PhD}$ degrees in Electrical Engineering from the Brno University of Technology, Czech Republic in 2005, 2007, and 2011, respectively. Currently, he is an Assistant Professor at the Department of Telecommunications. His research interests are focused on circuit applications of modern active elements such as current operational amplifiers and multiple-output current followers.

Radek Dvořák was born in Třebíc, Czech Republic. He received his MSc from Brno University of Technology in 2007. His research interests include alternative microwave measurement methods.

Aslihan Kartci is currently working toward the Bachelor of Engineering (BE) degree from the Department of Electronics \& Telecommunication Engineering, Corlu Engineering Faculty, Namik Kemal University, and from September 2010 through February 2011 she was an Erasmus exchange student with the Faculty of Electrical Engineering and Communication of Brno University of Technology, Brno, Czech Republic. Her research interests include signal processing and telecommunications.

Tomáš Dostál received his PhD (1976) and DrSc degree (1989). He was with the University of Defense Brno (19761978 and 1980-1984), with the Military Technical College Baghdad (1978-1980), with the Brno University of Technology (1984-2008) and with the European Polytechnic Institute (2008-2009). Since 2009 he has been with the College of Polytechnics, Jihlava as Professor of Electronics. His interests are in circuit theory, analog filters, switched capacitor networks and circuits in the current mode.

Kamil Vrba received the $\mathrm{PhD}$ degree in Electrical Engineering in 1976, and the Prof. degree in 1997, both from the Technical University of Brno. Since 1990 he has been Head of the Department of Telecommunications, Faculty of Electrical Engineering and Computer Science, Brno University of Technology, Brno, Czech Republic. His research work is concentrated on problems concerned with accuracy of analog circuits and mutual conversion of analog and digital signals. In cooperation with AMI Semiconductor Czech, Ltd. (now ON Semiconductor Czech Republic, Ltd.) he has developed number of novel active function blocks for analog signal processing such as universal current conveyor (UCC), universal voltage conveyor (UVC), programmable current amplifier (PCA), digitally adjustable current amplifier (DACA), and others. He is an author or co-author of more than 700 research articles published in international journals or conference proceedings. Professor Vrba is a Member of IEEE and IEICE. 